Supporting Information for

\title{
Design, Synthesis, Structure-Selectivity Relationship, and Effect on Human Cancer Cells of a Novel Series of Histone Deacetylase 6-Selective Inhibitors
}

\author{
Yukihiro Itoh, ${ }^{\dagger}$ Takayoshi Suzuki, ${ }^{*}{ }^{\dagger}$ Akiyasu Kouketsu, ${ }^{\dagger}$ Nobuaki Suzuki, ${ }^{\dagger}$ Satoko Maeda, ${ }^{\dagger}$ \\ Minoru Yoshida, ${ }^{\ddagger \S}$ Hidehiko Nakagawa, ${ }^{\dagger}$ and Naoki Miyata ${ }^{, \dagger}$
}

${ }^{\dagger}$ Graduate School of Pharmaceutical Sciences, Nagoya City University, 3-1 Tanabe-dori, Mizuho-ku, Nagoya, Aichi 467-8603, Japan

${ }^{t}$ RIKEN, Saitama 351-0198, Japan

${ }^{\S}$ CREST Research Project, Japan Science and Technology Agency, Saitama 332-001, Japan

\section{Elemental Analysis}
Compd
calcd
found
$11 \mathrm{~b} \quad \mathrm{C}_{26} \mathrm{H}_{36} \mathrm{~F}_{3} \mathrm{~N}_{2} \mathrm{O}_{6} \mathrm{~S} \cdot 1 / 4 \mathrm{H}_{2} \mathrm{O}$
C, 55.46; H, 6.00; N, 4.97
C, 55.33; H, 5.89; N, 4.84
$16 \mathrm{~b} \quad \mathrm{C}_{21} \mathrm{H}_{38} \mathrm{~N}_{2} \mathrm{O}_{4} \mathrm{~S} \cdot 1 / 3 \mathrm{H}_{2} \mathrm{O}$
C, 59.97; H, 9.27; N, 6.66
C, 59.91; H, 9.28; N, 6.79
$18 \mathrm{~b} \quad \mathrm{C}_{23} \mathrm{H}_{42} \mathrm{~N}_{2} \mathrm{O}_{4} \mathrm{~S} \cdot 1 / 2 \mathrm{H}_{2} \mathrm{O}$
C, 61.16; H, 9.60; N, 6.20
C, 62.23; H, 9.55; N, 6.32
$19 \mathrm{~b} \quad \mathrm{C}_{20} \mathrm{H}_{38} \mathrm{~N}_{2} \mathrm{O}_{4} \mathrm{~S} \cdot 2 / 3 \mathrm{H}_{2} \mathrm{O}$
C, 57.96; H, 9.56; N, 6.76
C, 57.86; H, 9.29; N, 6.89
$20 \mathrm{~b} \quad \mathrm{C}_{26} \mathrm{H}_{44} \mathrm{~N}_{2} \mathrm{O}_{4} \mathrm{~S}$
C, 64.96; H, 9.23; N, 5.83
C, 64.56; H, 9.18; N, 5.72 
